Received: 2015.04.15 Accepted: 2015.05.11 Published: 2015.10.13

\title{
Attitudes Concerning Postmortem Organ Donation: A Multicenter Survey in Various German Cohorts
}

Authors' Contribution: Study Design A Data Collection B Statistical Analysis C Data Interpretation D Manuscript Preparation E Literature Search F Funds Collection G

Corresponding Author: Source of support:

Background: Material/Methods:

Results:

Conclusions:

MeSH Keywords:

Full-text PDF:
Constantin Uhlig, e-mail: uhligc@uni-muenster.de Departmental sources
1 Department of Ophthalmology, University Clinics, Münster, Germany 2 Department of Ophthalmology, Eye Center, University Hospital, Freiburg, Germany 3 Department of Psycholinguistic and Neurosciences, University Clinics, Münster, Germany

4 Department of Ophthalmology, Saarland University Medical Center, Homburg Saar, Germany

5 Department of Transplantation, University Clinics, Münster, Germany

The aim of this study was to characterize postmortem organ donation attitudes in various German cohorts. Employees of 2 German cities and 2 German university hospitals, employees of a German automobile enterprise, and members of a German Medical Society were administered a questionnaire about postmortem organ and tissue donation attitudes. Demographic data and general attitudes were questioned and focused on: I) willingness to donate organs, II) holding a donor card, and III) having discussed the topic with the family. Of 5291 participants, $65.2 \%$ reported favoring postmortem organ donation. Missing negative experiences, the idea that donation is helpful, a non-medical professional environment, excellent general health, gender, agreement with the brain-death paradigm, and age significantly influenced the participants' attitudes. Participants were more likely to possess donor cards and had discussed more often with family members if they agreed with the brain-death paradigm and considered donation to be helpful. Males and older participants were the most likely to neglect donor cards, and Catholics, Protestants, and participants with poor health were the least likely to donate organs. Interest in receiving more information was expressed by $38.1 \%$ and $50.6 \%$ of participants refusing donation of all or of specific organs, respectively, and suggested the internet $(60.0 \%)$ and family doctors (35.0\%) as preferred sources of information.

Public campaigns in Germany should focus on males and older people as regards donor cards, and females, younger, and religiously affiliated persons as regards the general willingness to donate organs postmortem.

Organ Transplantation • Tissue and Organ Procurement • Transplantation, Homologous

http://www.annalsoftransplantation.com/abstract/index/idArt/894385

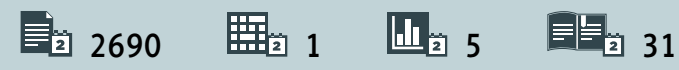




\section{Background}

The shortage of postmortem tissue and organ donation is a global problem that public health policies and private efforts (e.g., by religious organizations) have not resolved. The shortage is highly evident in Germany [1,2]. Various legal regulations in different countries reflect the uncertainty about which donation policy is best for ameliorating the shortage of donors [3-7]. For example, in the USA, physicians are required by law to ask family of deceased potential donors about organ donation. In Belgium and Italy consent is presumed. This means that citizens must opt out of postmortem donorship while still living. In Denmark, Germany, and the U.K. citizens must opt in by providing informed consent. In Germany, citizens are additionally routinely informed by their health insurance provider about organ donation and are motivated to decide while living [8,9]. Nevertheless, in Germany in 2012, 11 300 patients were waiting to receive a transplant [10], but only 1046 organs were transplanted. This reflects an ongoing decrease in the number of postmortem organ donors [11].

The aim of the present study was to interview potential organ donors in Germany with varying sociodemographic backgrounds, gender, age, religion, medical vs. non-medical employment, and academic vs. non-academic education, in an effort to represent a part of the German society. In contrast to our previously published reports about the willingness to donate corneas postmortem in the same cohorts [12-16], we here aimed to characterize attitudes regarding the general willingness to donate organs after death.

\section{Material and Methods}

As previously described [12-16], an anonymous questionnaire was created. To specifically focus on medically and non-medically educated citizens, the questionnaires were sent to employees of 2 German university hospitals and, in contrast, to administrative employees of 2 large central German cities, respectively. In addition to participants who were mainly assumed to have a university education, we also sent questionnaires to workers in a large German automobile enterprise. We also contacted members of the German Ophthalmological Society (DOG), primarily to know their attitudes about corneal donation, but also to obtain their responses to the complete organ and tissue questionnaire, and their statements regarding organ donation were included in this analysis.

Participation was voluntary, and the questions involved sociodemographic data and participants' attitudes for or against organ donation. Completed surveys were defined as those in which the final question of the questionnaire was answered. This method did not prevent missing answers within the questionnaire, so
Table 1. Sociodemographic data of the participants.

\begin{tabular}{|lc}
\hline $\begin{array}{l}\text { Sociodemographic data of the } \\
\text { participants }\end{array}$ & $62.6 \%$ \\
\hline Female & $37.4 \%$ \\
\hline Male & $13.8 \%$ \\
\hline$<30$ years & $56.3 \%$ \\
\hline $30-49$ years & $29.9 \%$ \\
\hline$>49$ years & $49.8 \%$ \\
\hline Catholic & $28.7 \%$ \\
\hline Protestant & $20.4 \%$ \\
\hline Without confession & $1.0 \%$ \\
\hline Different confessions & $68.8 \%$ \\
\hline With partnership & $31.2 \%$ \\
\hline Without partnership & $68.2 \%$ \\
\hline A-level & $31.8 \%$ \\
\hline Belowe A-level & \\
\hline
\end{tabular}

there were different numbers of responses among the participants. The authors adhered to the Declaration of Helsinki, and the ethics committee ruled that approval was not required for this anonymous and voluntary survey. Statistical analyses were performed using IBM SPSS 22 for Windows (IBM Corporation, Somers, NY, USA). To define more general attitudes irrespective of the different cohorts, multivariate logistic regression was performed with the following outcomes: I) willingness to donate postmortem organs (heart, lungs, liver, kidneys, pancreas, stomach, and colon); II) holding an organ donor card; and III) having discussed the topic with family. Independent parameters were as follows: family status (partnership vs. no partnership), gender (female vs. male), age ( $<30$ years, 30-49 years, or $>49$ years), professional environment (medical vs. non-medical), level of education (A levels vs. below A levels), religion (Catholic, Protestant, or atheist), faith in eternal life, general health status, former experiences with donation (positive vs. negative), estimation of the medical value of donating tissue and organs (medically valuable for the recipient vs. not valuable), confidence in brain-death diagnostics, fear of organ/tissue commercialization, and fear of receiving worse medical treatment as a postmortem donor. Responses associated with the latter 5 variables were divided into 3 categories: "tendency to favor", "neutral", and "tendency not to favor".

Multivariate logistic regression was also performed with the same parameters as described above for the willingness to donate specific organs. 


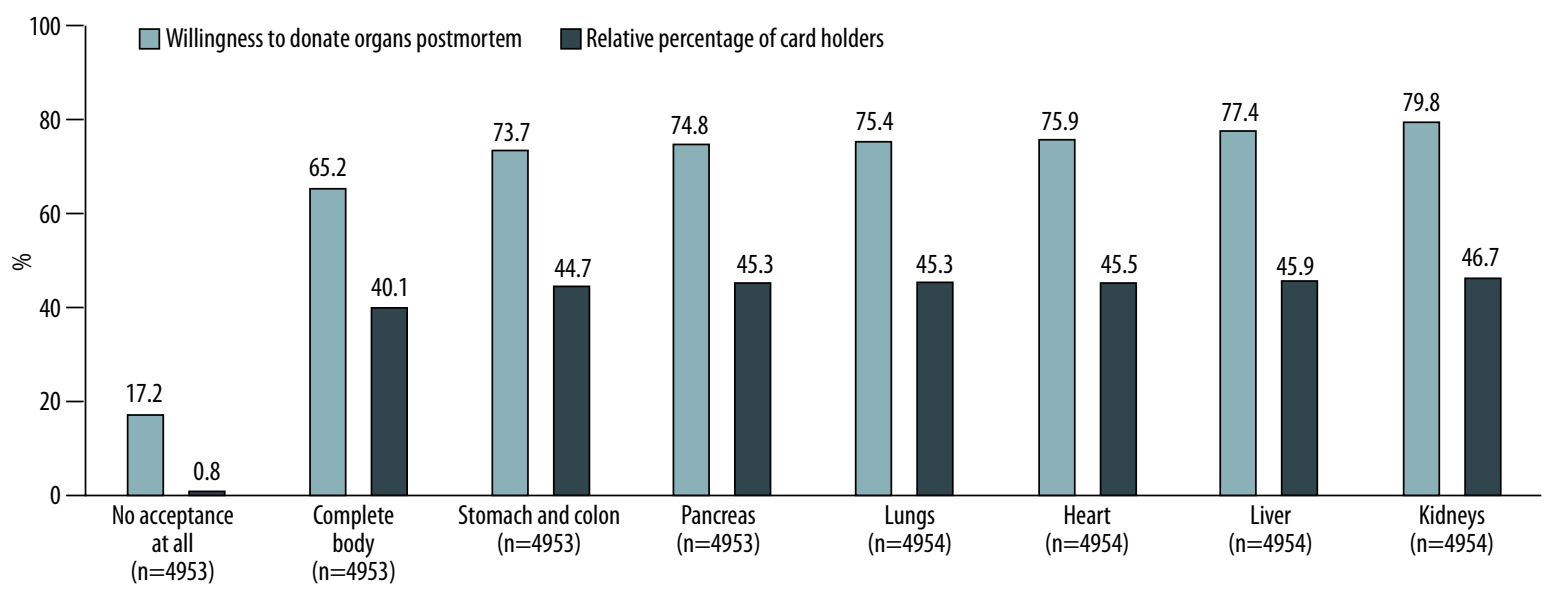

Figure 1. Acceptance of organ donation and the relative percentages of organ donor card holders among various patient groups.

\section{Results}

\section{Demographic results}

The respondents included 2820 out of 12837 employees at university hospitals, 1690 out of 11122 administrative employees, 614 out of 3887 members of the ophthalmological society, and 303 out of 4613 employees at the automobile enterprise, which presents $52 \%, 31 \%, 11 \%$, and $6 \%$, respectively, of all participants. Further details as regards the demographic characteristics of the cohorts and the submitted questionnaires are partially presented in Table 1 , and have mainly been published elsewhere $[14,16]$.

\section{General attitudes toward postmortem organ donation}

A total of $65.2 \%$ of the respondents indicated they would consent to postmortem donation of all organs (Figure 1), whereas $17.2 \%$ of the respondents would not consider organ donation at all. A total of $17.6 \%$ of the respondents were willing to donate specific organs, out of which $73.7 \%$ who would donate the stomach and colon, $74.8 \%$ who would donate the pancreas, $75.4 \%$ who would donate the lungs, $75.9 \%$ who would donate the heart, $77.4 \%$ who would donate the liver, and $79.8 \%$ who would donate the kidneys.

The $37 \%$ of all participants who are willing to donate their complete body stated that they want be able to specify which organs to donate. It is also important to $62.8 \%$ of all participants who are not willing to donate organs that a potential donor should be able to specify which organ(s) to donate $(p<0.001$, Fisher's exact test).

Among the participants who opt not to donate, $57.1 \%$ had discussed their decision with their families (Figure 2). However, only $5.7 \%$ of these participants had a donor card. In contrast,

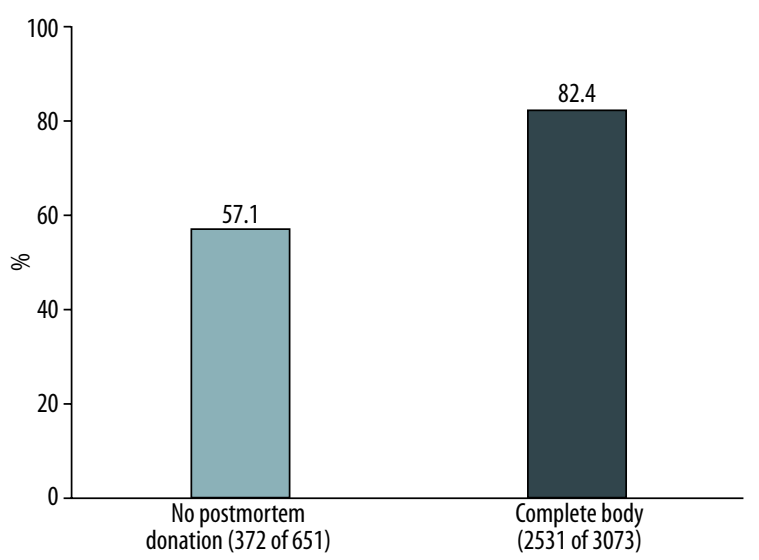

Figure 2. Percentages of participants who chose not to donate postmortem organs or chose to donate all of their organs and had already discussed their intentions with their families.

$82.4 \%$ of participants who declared their intention to donate all of their organs had already discussed the matter with their families, and $84.1 \%$ of these participants had a donor card. The difference between participants opting for or against donating all organs as regards "having a donor card" or "having already discussed with their family" were statistically significant ( $p<0.001$ for both groups).

A total of $21.1 \%$ of the automobile workers, $46.3 \%$ of the administrational employees, $52.5 \%$ of the university employees, and $55.8 \%$ of the ophthalmological society members reported having a donor card [12]. 


\section{Multivariate logistic regression}

\section{I) Willingness to donate the whole body postmortem}

Logistic regression revealed that the following factors significantly increased the probability of consenting to postmortem organ donation: no prior negative experiences with organ donation, not working in a medical environment, excellent general health, male gender, advanced age, the belief that donated organs are medically useful for the patients, and agreement with the brain-death paradigm (Figure 3A). Being Catholic or Protestant were negative predictors of organ donation compared with being atheist. Further significant negative predictors were fear of organ commercialization and fear of receiving suboptimal medical treatment as a potential organ donor. Having faith in an afterlife, family status, and higher vs. no higher education were not statistically significant (Figure 3A).

\section{II) Possessing a donor card}

Logistic regression revealed that agreement with the brain death paradigm and the belief that donated organs are useful are significant positive predictors of possessing a donor card (Figure 3B). Fear of organ commercialization, male gender, and advanced age made it significantly less likely to possess a donor card. Religious affiliation, general health, previous experiences with organ donation, faith in eternal life, partnership, medical vs. non-medical working environment, and higher vs. no higher education lacked statistical significance (Figure 3B).
$92.6 \%$ of the medically affiliated and $93.5 \%$ of the non-medically affiliated participants, respectively, who had already filled out a donor card had also already communicated their donation attitude to their relatives. Participants who did not possess a donor card had communicated their attitudes in $62.1 \%$ and $58.03 \%$. Interestingly, only $66.1 \%$ of the medically and $54.2 \%$ of the non-medically affiliated participants, respectively, who were willing to donate their complete body postmortem also possessed a donor card.

\section{III) Discussions with the family}

Logistic regression revealed that agreement with the brain death paradigm and the idea that donated organs are useful were significant positive predictors of having discussed organ donation with the family. Fear of organ commercialization, fear of suboptimal medical treatment when being a potential organ donor, being Catholic in comparison to being atheist, male gender, living without a partner, and no prior negative experiences with organ donation were significant negative predictors of having discussed organ donation with the family. Faith in eternal life, general health, age, education, protestant vs. atheist, and medical vs. non-medical working environment were not statistically significant (Figure 3C).

\section{Differences between cohorts willing to donate their complete body, specific organs, or nothing at all}

In comparison to those participants who were willing to donate their complete body postmortem, male participants were

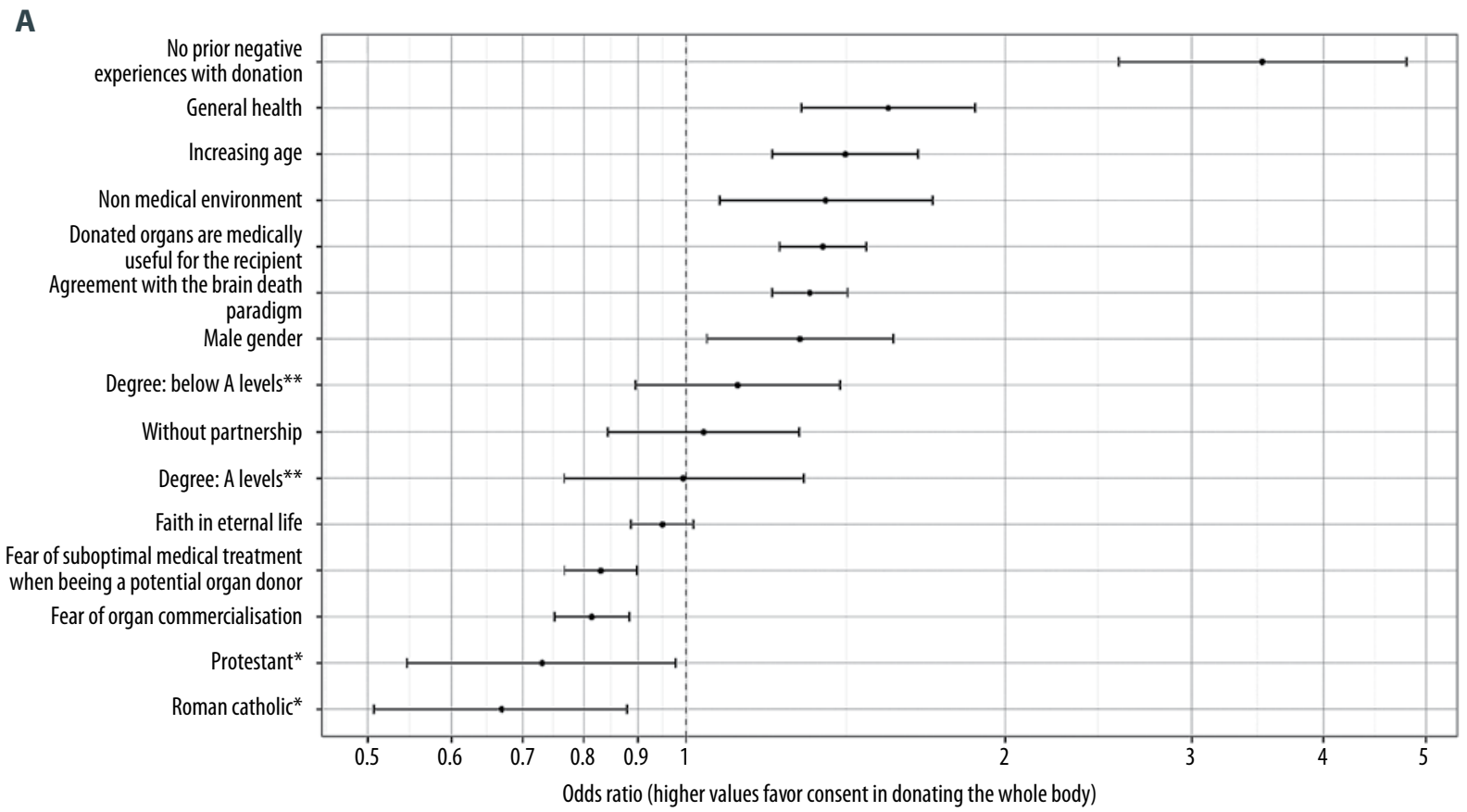


B

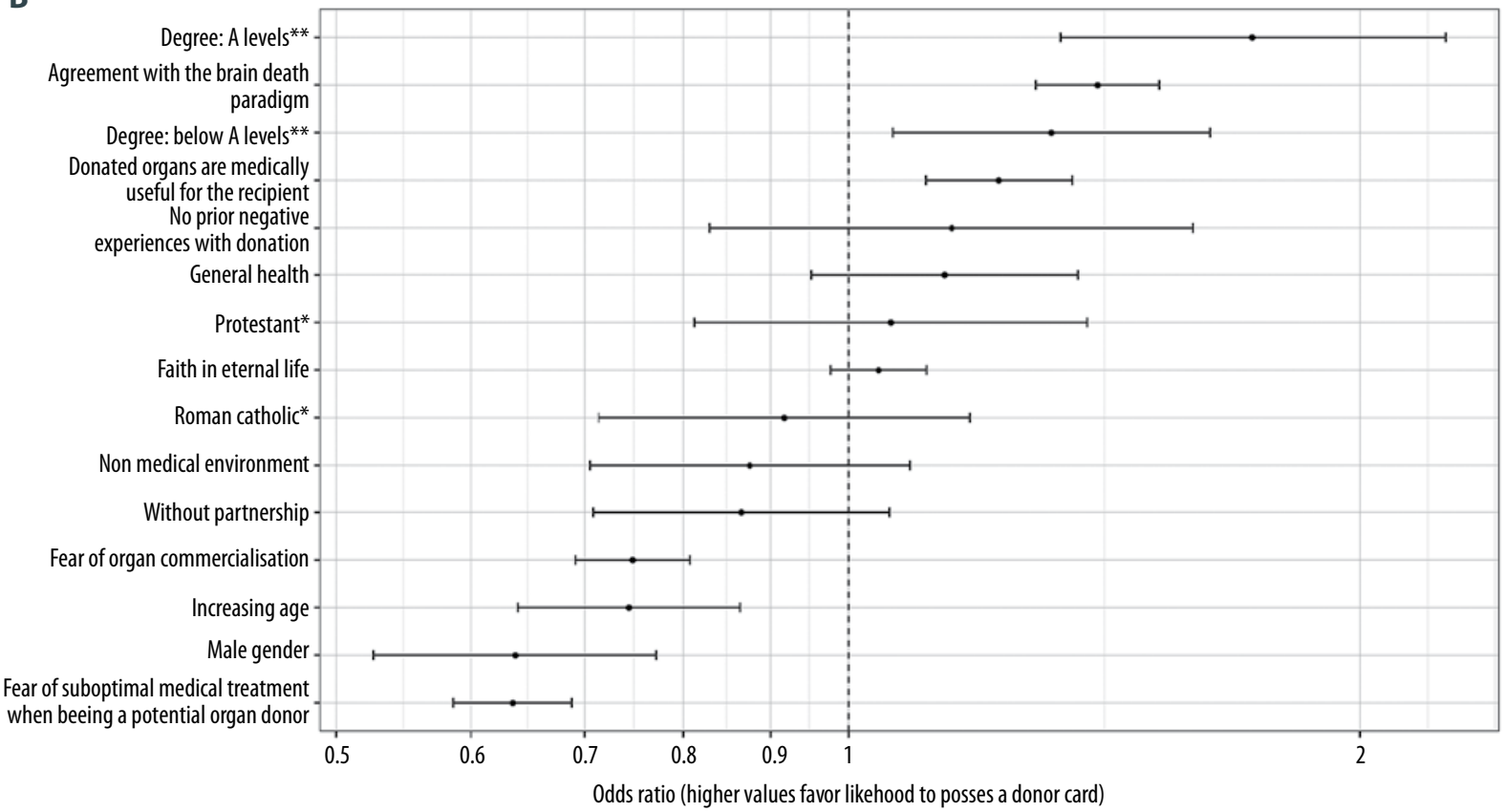

C

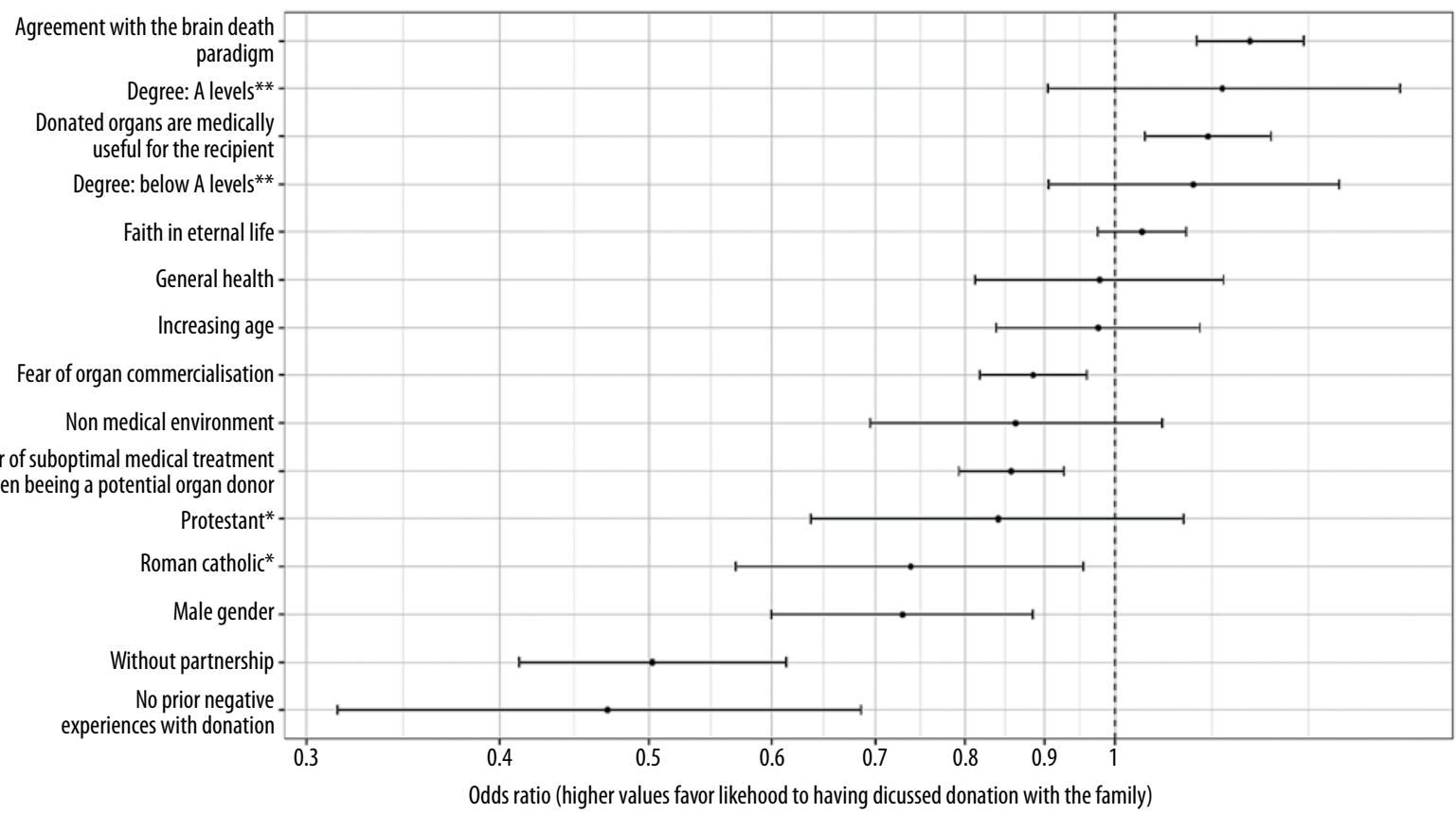

Figure 3. Odds ratios in a multiple logistic regression analysis that predict: (A) the likelihood to donate the whole body postmortem, (B) the likelihood to possess a donor card, and (C) the likelihood of having already discussed with a next of kin the intention to donate organs postmortem. Higher odds ratios (x-axis) reflect higher likelihoods. * in comparison to atheists, and ${ }^{* *}$ in comparison to university diploma-holders.

especially unwilling to donate particular organs: liver (OR: 0.63; 95\% Cl: 0.51-0.78), lungs (OR: 0.65; 95\% Cl: 0.49-0.86), kidneys (OR: 0.75 ; $95 \% \mathrm{Cl}: 0.60-0.99$ ), pancreas (OR: $0.63 ; 95 \% \mathrm{Cl}$ : $0.48-0.83$ ), and stomach and colon (OR: 0.58 ; $95 \% \mathrm{Cl}: 0.46-0.75$ ).
Comparatively elderly participants were less willing to donate these specific organs (OR: 0.21-0.51), including their heart (30-49 years: OR: $0.50 ; \mathrm{Cl}: 0.37-0.67 ;>50$ years: OR: 0.27 ; $\mathrm{Cl}: 0.18-0.41)$. Catholics and Protestants voted more often 

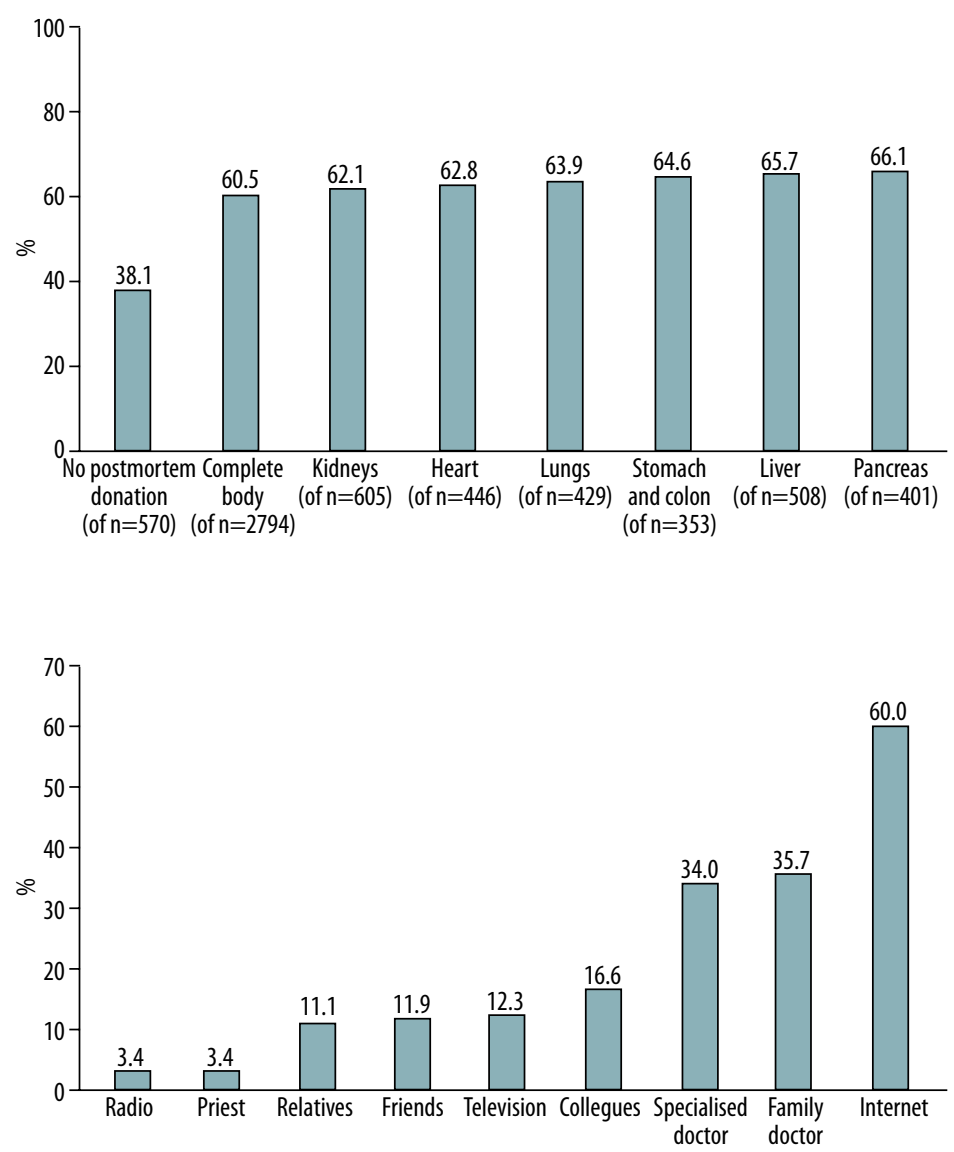

Figure 4. Percentages of participants donating either nothing, or the whole body, or only specific organs, who wanted to be better informed about donation and transplantation.
Figure 5. Percentages of participants who chose not to donate organs and preferred sources of information about postmortem organ donation and transplantation. than atheists to specifically donate their hearts (OR in both religions: 1.53 ; $p<0.001$ ) and kidneys (OR in Catholics: 1.60 ; OR in Protestants: 1.52 ; $p<0.05$ for both groups), while participants with A-level refused more often to specifically donate their heart (OR0.742; $\mathrm{Cl}: 0.56-0.98$ ) or their kidneys (OR: 0.77; $\mathrm{Cl}$ : 0.59-0.99).

\section{Request for information about donation and transplantation}

A total of $60.5 \%$ (1691 of 2794) of participants who were willing to donate all of their organs, $38.1 \%$ (217 of 570) of participants who chose not to donate any of their organs, and $50.6 \%$ (635 of 1256 ) of participants who were not ready to donate all their organs were interested in receiving additional information about transplantation and donation (Figure 4).

Nevertheless, $60.0 \%$ of the participants who chose not to donate postmortem organs indicated the internet as an appropriate source of information about the topic, whereas only $11.1 \%$ and $11.9 \%$ indicated family and friends, respectively, as appropriate sources of information (Figure 5).

\section{Discussion}

Recently, Kirchner et al. [17] calculated that there is substantial potential to increase organ donation rates in Germany. In the present study we aimed to identify factors that affect the decision to donate organs, to possess a donor card, or to talk with the family members about the topic of donation and transplantation. Additional knowledge on donation preferences might improve attempts to educate the general public about organ donation and to improve the willingness to donate postmortem.

A 2012 questionnaire revealed that $81.0 \%$ of medical employees in Germany favor organ donation, but only $45.3 \%$ of them were organ donor card holders [11]. Similarly, Rey et al. observed that $63 \%$ of a German secondary school's students had a positive attitude toward donation, but only $11.3 \%$ of the students possessed an organ donor card [18]. Heuer et al. observed that only $21 \%$ of public officials in a major German city were donor card holders [19]. Their results were consistent with the findings of Beutel et al., in which a representative survey of German citizens revealed that only $21 \%$ were card holders [20]. We observed a much higher percentage of donor card holders in our German cohorts, which might result from continuous official education. 
The results in our cohorts did not reveal strong influences of religiousness. This differs from the surveys among students in multicultural societies such as Israel [21] and Australia [22,23] and might result from our more religiously homogenous cohorts, or from less meaningful questions ("to be religiously affiliated" and "religion"). Moreover, our observations were focused on participants mostly originating from central Europe. Nevertheless, they do not completely reflect the observations of Beutel et al. [20], in which elderly individuals with less education were more likely to donate organs postmortem.

Our results demonstrate that emotional parameters such as confidence in the diagnosis of brain death, fear of insufficient medical treatment, or anxieties about the commercialization of donated organs are still relevant in relation to attitudes about postmortem organ donation. This is despite national and regional campaigns that have been conducted in the past [20,24-26]. Our observation is consistent among the medically affiliated participants. This corresponds to a survey by Söffker et al. [11] and observations from Bastami et al. The latter concluded that "deep-rooted concerns about organ donation after cardiac death exist among medical personnel and the general public" [27].

The differences between our survey respondents who were either willing to donate all of their organs or who were willing to donate only specific organs are in line: Male or elderly participants were comparatively more often willing to donate their complete body postmortem, and females or younger participants were more likely to donate only specific organs.

We observed that a lower willingness to donate was correlated with participants who had not discussed the topic with their families. This was also reported by Siminoff et al., who found that organ donation consent was lower among families that had not discussed the patients' decisions [28]. Nevertheless, our results do not prove that lower acceptance rates are linked to a lack of family discussions, nor do they prove that lack of discussion is a result of donation refusal. In this context, West and Burr concluded from a literature review that many families chose not to donate because of misunderstandings about brain death, cultural beliefs, timing of the request, and the deceased's attitude toward donation [29].

In our study, predicting the willingness to donate organs postmortem was also dependent on rational information. A partial or complete lack of rational knowledge is not surprising in regions with less media presence, such as Saudi Arabia. There, more than $90 \%$ of survey respondents in rural and urban areas reported having little knowledge about the topic [30]. However, in industrialized countries such as Germany, these results are surprising; one solution is to use the internet to distribute information more broadly. Interestingly, this was also suggested by the survey participants, even those who are still against donation.

Questionnaires about organ donation have limitations for various reasons. One such reason is the response bias, which depends on how the questions were designed and the knowledge and understanding of the participants, which makes it difficult to estimate how well the questions and answers represent the related topic. Furthermore, there may have been a response bias if individuals with specific attitudes towards organ donation were less likely to participate.

Our finding may differ from previous reports $[19,20]$ due to the age, experience, and education of our survey respondents. Although our questionnaire was presented to different German cohorts with various sociodemographic backgrounds, our results are not fully representative of the complete German society, since, for example, no rural population was represented. Importantly, we did not send our survey to individuals who had recently lost a family member. Therefore, our observations may not reflect the effective organ donation rate, where relatives often change their minds after the death and this may have a negative effect on donation rate [31]. On the other hand, our data may better reflect possible willingness to donate postmortem, for example, in case of clearly documented willingness of potential donors.

\section{Conclusions}

Our results are important because we included several German regions and focused on participants with different age, gender, religion, education, and medical affiliation. Additionally, in comparison to previous reports [11,18-20], the response rate in our survey was very large. In that, we may hypothesize, but cannot prove, that results would be similar in countries with comparable sociodemographic, economic and legal backgrounds. This seems to be most probable in central or northern Europe but has to be analyzed in future investigations. Our data from these particular cohorts suggest specifically contacting females and younger persons about general willingness to donate postmortem, but contacting males and older people about donor cards. Religious institutions and church officials should also intensify communication on this topic. Our results additionally suggest the need for help from official internet platforms and cooperation with family doctors. Furthermore, information should also be spread in professional medical institutions to their employees, and generally address both medico-legal and emotional parameters, including specifically that organ commercialization is prohibited, medical procedures guarantee a correct diagnosis for clinical death, and postmortem organ donors do not undergo additional risk or suffering. 


\section{Conflicts of interest}

The authors declare no conflicts of interest.

\section{References:}

1. Transplantationsgesetz in der Fassung der Bekanntmachung vom 4 September 2007 (BGBI. I S. 2206), das zuletzt durch Artikel 5d des Gesetzes vom 15. Juli 2013 (BGBI. I S. 2423) geändert worden ist. Bundesanzeiger Verlag $\mathrm{GmbH}$, Köln [in German]

2. Deutsche Bischofskonferenz/Rat der EKD. Erklärung der Deutschen Bischofskonferenz und des Rates der EKD zu Organstransplantationen: http://www.ekd.de/EKDTexte/organtransplantation_1990.html; accessed on: April, 06, 2015 [in German]

3. Bendorf A, Kelly PJ, Kerridge $\mathrm{IH}$ et al: An international comparison of the effect of policy shifts to organ donation following cardiocirculatory death (DCD) on donation rates after brain death (DBD) and transplantation rates. PloS One, 2013; 8: e62010

4. Randhawa G, Brocklehurst A, Patema R et al: 'Opting-in or opting-out?' - the view of the UK's faith leaders in relation to organ donation. Health Policy, 2010; 96: 36-44

5. Rieu R: The potential impact of an opt-out system for organ donation in the UK. J Med Ethics, 2010; 36: 534-38

6. Mercer L: Improving the rates of organ donation for transplantation. Nurs Stand, 2013; 27: 35-40

7. Davidai S, Gilovich T, Ross LD: The meaning of default options for potential organ donors. Proc Natl Acad Sci USA, 2012; 109: 15201-5

8. Eurotransplant. Legislation within the Eurotransplant region. http://www. eurotransplant.org/cms/index.php?page=legislation 1, accessed on April, 06 2015

9. DSO. Das Deutsche Transplantationsgesetz. http://www.dso.de/organspendeund-transplantation/gesetzliche-grundlagen.html, accessed on April, 06, 2015 [in German]

10. Samuel U: [Organ donation - course of events.] Med Klin Intensivmed Notfmed, 2013;108: 437-45 [in German]

11. Söffker G, Bhattarai M, Welte $T$ et al: [Attitude of intensive care specialists toward deceased organ donation in Germany: Results of a questionnaire at the $12^{\text {th }}$ Congress of the German Interdisciplinary Association for Intensive and Emergency Medicine.] Med Klin Intensivmed Notfmed, 2013; 109: 41-47 [in German]

12. Uhlig CE, Promesberger J, Hirschfeld G et al: [Results of an internet-based survey amongst members of the German Ophthalmological Society concerning postmortem cornea donation.] Ophthalmologe, 2012; 109: 1198-206 [in German]

13. Schulte B: Evaluation medizinischer Einflussfaktoren auf die Hornhautspende. Inaugural-Dissertation, Medizinische Fakultät der Westfälischen WilhelmsUniversität Münster, 2012, Münster [in German]

14. Uhlig CE, Koch R, Promesberger J et al: Attitudes toward postmortem cornea donation in Germany: a multicenter survey. Graefe's Arch Clin Exp Ophthalmol, 2014; 252: 1955-62

15. Brockhaus R: Evaluation soziokultureller Einflüsse auf die Hornhautspendebereitschaft. Inaugural-Dissertation, Medizinische Fakultät der Westfälischen Wilhelms-Universität Münster, 2015, Münster [in German]
16. Uhlig CE, Seitz B, Eter $\mathrm{N}$ et al: Efficiencies of Internet-based digital and paper-based scientific surveys and the estimated costs and time for different-sized cohorts. PloS One, 2014; 9: e108441

17. Kirchner C, Raduenz S, Fruehauf NR et al: Estimated organ donation potential in German maximum care hospitals. Transplant Proc, 2013; 45: 1310-12

18. Rey JW, Grass V, Barreiros AP et al: Organ procurement in Germany: a regional survey amongst students. Dtsch Med Wochenschr, 2012; 137: 69-73 [in German]

19. Heuer $M$, Remmer N, Radünz $S$ et al: [Disposition for organ donation: Analysis of a survey and trial of 974 respondents.] Zentralbl Chir, 2012 138: 598-603 [in German]

20. Beutel ME, Greif-Higer G, Haselbacher A et al: Attitudes towards cadaveric organ donation - results from a representative survey of the German population. Z Gastroenterol, 2006; 44: 1135-40 [in German]

21. Khailaila R: Religion, altruism, knowledge and attitudes toward organ donation: a survey among a sample of Israeli college students. Med Law, 2013 32: $115-29$

22. Weiland TJ, Marck CH, Jelinek GA et al: Attitudes of Australian emergency department clinicians toward organ and tissue donation: an analysis of cultural and religious influences. Prog Transpl, 2013; 23: 278-89

23. Gauher ST, Khehar R, Raiput G et al: The factors that influence attitudes toward organ donation for transplantation among UK university students of Indian and Pakistani descent. Clin Transplant, 2013; 27: 359-67

24. Demir T, Selimen D, Yildirim M, Kucuk HF: Knowledge and attitudes toward organ/tissue donation and transplantation among health care professionals working in organ transplantation or dialysis units. Transplant Proc, 2011; 43: $1425-28$

25. Flodén A, Persson LO, Rizell $M$ et al: Attitudes to organ donation among Swedish ICU nurses. J Clin Nurs, 2011; 20: 3183-95

26. Long T, Sque M, Addington-Hall J: What does a diagnosis of brain death mean to family members approached about organ donation? A review of the literature. Prog Transplant, 2008; 18: 118-25

27. Bastami S, Matthes O, Krones T, Biler-Andoro N: Systematic review of attitudes toward donation after cardiac death among health providers and the general public. Crit Care Med, 2013; 41: 897-905

28. Siminoff LA, Gordon N, Hewlett J, Arnold RM: Factors influencing families' consent for donation of solid organs for transplantation. JAMA, 2001; 286: 71-77

29. West R, Burr G: Why families deny consent to organ donation. Aust Crit Care, 2002; 15: 27-32

30. Alghanim SA: Knowledge and attitudes toward organ donation: a community based study comparing rural and urban populations. Saudi J Kidney Dis Transpl, 2010; 21: 23-30

31. Wesslau C, Grosse K, Krüger R et al: How large is the organ donor poten tial in Germany? Results of an anylsis of data collected on deceased with primary and secondary brain damage in intensive care unit from 2002 to 2005. Transpl Int, 2007; 20(2): 147-55 